\title{
Correction: A patient-derived xenograft pre-clinical trial reveals treatment responses and a resistance mechanism to karonudib in metastatic melanoma
}

Berglind O. Einarsdottir, Joakim Karlsson (1), Elin M. V. Söderberg, Mattias F. Lindberg, Elisa Funck-Brentano,

Henrik Jespersen, Siggeir F. Brynjolfsson @, Roger Olofsson Bagge, Louise Carstam, Martin Scobie, Tobias Koolmeister, Olof Wallner, Ulrika Stierner, Ulrika Warpman Berglund, Lars Ny, Lisa M. Nilsson, Erik Larsson, Thomas Helleday and Jonas A. Nilsson

\section{Correction to: Cell Death and Disease https://doi.org/10.1038/s41419-018-0865-6, published online 24 July 2018}

On Pubmed, the name of co-author Roger Olofsson Bagge appeared incorrectly as "Bagge RO" instead of "Olofsson Bagge, Roger".
This has been corrected in the PDF and HTML versions.

Published online: 06 February 2020 